\title{
Survivin Positive
}

National Cancer Institute

\section{Source}

National Cancer Institute. Survivin Positive. NCI Thesaurus. Code C131872.

An indication that survivin expression has been detected in a sample. 